\title{
PARA ENTENDER A RELAÇÃO ESCOLA-FAMÍLIA uma contribuição da história da educação
}

\author{
Luciano Mendes de Faria Filho \\ Professor da FaE-UFMG, Coordenador do GT História da Educação/ANPEd
}

\begin{abstract}
Resumo: O texto pretende contribuir com as discussões sobre a relação entre a escola e a família, analisando a forma como nas páginas de um periódico mineiro, a Revista do Ensino, cujos responsáveis se auto-reconheciam como escolanovistas, um grupo bastante diversificado de sujeitos (professores, técnicos de ensino, diretores de instrução...) concebia e colocava em circulação a temática das relações entre essas duas instituições. Palavras-chave: educação e sociedade; história da educação; imprensa no Brasil.
\end{abstract}

A relação entre a escola e a família é, sobretudo nos dias de hoje, uma das mais palpitantes questões discutidas por pesquisadores e/ou gestores dos sistemas e unidades de ensino em quase todo o mundo. Este fato é evidenciado, por um lado, pelo expressivo número de pesquisas e publicações especializadas sobre $\mathrm{o}$ assunto, e, por outro, pela preocupação manifestada nos mais diversos fóruns (de reuniões escolares a fóruns nacionais e internacionais) pelos profissionais responsáveis por gerir simples unidades escolares ou complexos sistemas nacionais de ensino.

No campo das pesquisas acadêmicas, talvez a área que mais tem se voltado para o estudo e entendimento das relações entre escola e família seja, não por acaso, a Sociologia e, subalternamente, os estudos de políticas de educação. Discutindo seja temas clássicos, como o fracasso escolar, seja questões recentemente incorporadas, como as trajetórias escolares, os sociólogos da educação têm continuamente chamado a atenção para a implicação da instituição familiar com a escola. Como dizem Montandon e Perrenoud (1987:7), “de uma maneira ou de outra, onipresente ou discreta, agradável ou ameaçadora, a escola faz parte da vida cotidiana de cada família".

Todos estes estudos e, mais ainda, a prática pedagógica dos professores e gestores da escola põem em evidência um fato: a forma e a intensidade das relações entre escolas e famílias variam enormemente, estando relacionadas aos mais diversos fatores (estrutura e tradição de escolarização das famílias, classe social, meio urbano ou rural, número de filhos, ocupação dos pais, etc.).

Constata-se, também, um outro elemento: seja devido a mudanças pelas quais nas últimas décadas têm passado a família, seja em face das constantes e, às vezes, radicais alterações observadas na escola, bem como da conseqüente discussão (e incertezas) acerca do lugar dessas instituições na formação das novas gerações, observa-se hoje uma exaltação da necessidade de se estabelecer um efetivo diálogo entre a escola e a família.

Os professores e os gestores das unidades escolares alimentam, ainda, a ilusão de uma maior participação dos pais na escola, que seria resultado de uma ação formativa da escola em relação à família. Centrados em uma visão escolarizada do problema, eles não põem em dúvida o lugar construído para e pela escola, em relação às demais instituições sociais, dentre elas a família.

É no interior deste debate, antigo e muito mais complexo do que aqui apresentado, que se inscreve a preocupação dos historiadores da educação com o tema. No Brasil, ao longo do século XIX, a instituição escolar vai lenta, mas inexoravelmente, se fortalecendo como o locus fundamental e privilegiado de formação das novas gerações, estando diretamente relacionados a este fato a expansão da escolarização, o processo de profissionalização do 
magistério primário, dentre outros fatores (Faria Filho, 1999). Neste processo, ela desloca, como já foi observado por diversos autores (Alvares-Uria e Varela, 1991; Vicent, 1994), outras instituições (família, igreja, etc.) de seus lugares tradicionais de socialização, considerandoas, na maioria das vezes, incapazes de bem educar diante de uma sociedade que se urbaniza e se complexifica, que supõe novas dinâmicas e padrões de comportamento.

Por outro lado, estudos têm detectado também que, nas primeiras décadas do século XX, o afastamento da família da escola, resultante em boa parte da ação dos defensores e instituidores da escolarização, é uma preocupação constante destes mesmos agentes (Faria Filho, 2000). Postados no interior de um campo que ganhava cada vez mais especificidade e legitimidade, os professores e outros agentes da educação passam a reclamar do desinteresse dos pais, principalmente das camadas populares, para com a educação dos filhos. A partir de diagnósticos os mais variados, baseados na premissa de que, embora seja fundamental a participação das famílias na educação dos filhos, estas demonstravam, naquele momento, um profundo desinteresse e despreparo para lidar com o assunto, buscava-se projetar e desenvolver ações que visavam reaproximar a família da escola. No seu conjunto, em suas mais diversas elaborações, estas ações mostram uma intenção colonizadora da escola em relação à família, entendida esta tarefa como um momento fundamental da ação reformista da escola em face da realidade social mais ampla.

Este trabalho trata de um período em que ocorre uma intensificação das discussões na área, procurando verificar como os escolanovistas mineiros enfocavam a questão da relação entre escola e família. $O$ interesse por desenvolvê-lo deve-se, mais especificamente, ao fato de que em Minas Gerais, ao longo do primeiro quartel do século $\mathrm{XX}$, ao fazerem referências à escola nova, alguns professores e intelectuais dão maior relevo a experiências que exaltam a importância da instituição familiar na educação moral, intelectual e física das crianças. ${ }^{1}$

Para tanto, optou-se não por analisar toda a vasta produção do que aqui está sendo chamado, de forma demasiadamente elástica e imprecisa, de "movimento escolanovista mineiro", mas tão-somente por enfocar o assunto a partir do que foi posto em circulação no principal periódico mineiro à época, a Revista do Ensino, órgão oficial da Diretoria de Instrução Pública do Estado de Minas Gerais, e principal divulgador das idéias escolanovistas no Estado, abrangendo o período que vai desde sua cria- ção (1925) até o momento em que o principal mentor da reforma de ensino que ocorre em Minas Gerais, em 1927, Francisco Campos, deixa o cargo de secretário do Interior (1930). O período começa, portanto, antes de uma grande reforma de educação, tida pelos escolanovistas brasileiros como uma das principais do período, e termina quando as referências da reforma estão plenamente postas em circulação através da revista.

A escolha por se trabalhar este periódico, no entanto, não se deve somente a estas razões. Por um lado, está se assumindo aqui a posição, de forma exemplar explicitada e trabalhada por Marta Carvalho (1994), quanto à importância de se estudar os impressos pedagógicos para o entendimento das diversas dimensões do fazer pedagógico e da atuação dos agentes no campo educativo. Por outro lado, no projeto pesquisa está sendo desenvolvido na Universidade Federal de Minas Gerais, ${ }^{2}$ duas pesquisadoras estão trabalhando com esta revista: Maurilane Biccas (1999), que trata do lugar ocupado pela revista na "formação de professores e na conformação do campo pedagógico em Minas Gerais", compreendendo o período de 1925 a 1940; e Rita de Cássia de Souza (1999), que está estudando as representações e as práticas a respeito da disciplina escolar dos alunos, postas em circulação e legitimadas pelo periódico. De forma direta, este trabalho beneficia-se de ambos, assim como das produções recentes sobre a escola nova no Brasil e na América Latina (Carvalho, 1998; Nunes, 1993; Gvirts, s.d.), principalmente nas discussões sobre as propostas e estratégias de reforma social postas em ação pelos movimentos escolanovistas.

\section{ESCOLA E FAMÍLIA NA REVISTA DO ENSINO}

Em trabalho recente, Marcus Vinicius da Cunha (1996:318) "analisa o discurso educacional renovador veiculado no Brasil, entre 1944 e 1960, com vistas a discutir os referenciais utilizados para compreender as relações entre escola e família", tomando como base de sua pesquisa os artigos veiculados pela Revista Brasileira de Estudos Pedagógicos, no período em questão. Cunha observa que há uma predominância do enfoque de cunho histórico-sociológico no início do período analisado, o qual dá lugar a um claro psicologismo ao final.

Entretanto, em outra pesquisa (Faria Filho, 1999), que trata de um período anterior ao analisado por Cunha, não se observou tal movimento, nem a presença de refinadas discussões como aquelas encontradas por ele nos artigos 
analisados. ${ }^{3}$ Percebeu-se, inicialmente, que para os autores, dentre eles professores, dos textos publicados pela Revista do Ensino - e, portanto, para os próprios responsáveis pela mesma -, há uma clara consciência da importância da família na educação, que aparece das mais diversas formas e no interior de textos que tratam de assuntos variados. Há, no entanto, uma constante: a relação entre escola e família é, sempre, relacionada às mudanças sociais em curso, à vida na cidade e à necessidade do concurso de ambas para a formação do cidadão-trabalhador, higiênico e ordeiro.

Num artigo sobre o "Calendário Escolar", o professor Firmino Costa, diretor técnico do Curso de Aplicação, afirma:

“A vida social completa está na cidade. A família e a escola são suas partes mais importantes. A cidade há de interessar-se por elas, cooperando em seu desenvolvimento, pois que de outra forma não podem progredir. Onde não houver famílias bem constituídas, onde não existir escolas bem organizadas, aí não se encontrará a civilização. (...)

A família, a escola e a cidade hão de ver no menino uma esperança da pátria, donde deve brotar um cidadão digno e prestante. Elas têm de oferecer para esse fim um ambiente favorável, cuja formação compete aos professores e a todos aqueles que forem modelos da vida social" (Ano IV, 35, 1929, p.57-58).

No número posterior da revista, a publicação de uma tradução de um capítulo do livro Vers l'école de demain, de Angelo Patri, é ocasião para se retomar a questão da cidade, da rua, da violência nos processos de socialização. Na parte traduzida, referente ao capítulo III do livro de Patri, e publicada sob o título de "Fora da Escola", traz uma reflexão do autor sobre as dificuldades enfrentadas no trato com a violência do "em torno" à sua escola. Dizia, finalmente, desanimado:

"Então, pensava - será que minha escola é de fato diferente das outras? Não, por certo, continua a ser sempre a velha escola. Professores e meninos, ruas e desordens, têm aqui outros nomes, mas sãos os mesmos em toda parte. A família fecha-se em casa e ao mesmo tempo se separa do mundo. A escola fecha-se sobre si mesma, e não se incomoda pelo que vai fora. Mas a rua continua a agitar a multidão estrepitosa de sua vida, arrastando nossos filhos diante de nossas portas fechadas" (Ano IV, 36, 1929, p.19).

Também o tradutor, o assistente técnico de ensino Levindo Furquim Lambert, aproveita essa oportunidade para, ao comentar o texto traduzido, externar seu ponto de vista sobre o assunto:

"O lar forma, no estreito âmbito da casa, um mundo à parte, independente, regido talvez por leis reacionárias e dispersivas. E é bem por isso que a rua impressiona Angelo Patri. A escola deve completar a tarefa do lar, o aperfeiçoamento do caráter, encaminhando as tendências individuais para a harmonia e a estabilidade sociais" (Ano IV, 36, 1929, p.22).

A ação da família é, no entanto, uma ação complementar à da escola e a ela subordinada, porque se desconfia da competência da família para bem educar; na verdade, no mais das vezes, afirma-se que a família não consegue mais educar os seus filhos. A esse respeito, o grande problema, detectado nas páginas da revista, é que os pais não se interessam em participar da escola, pois dela estão afastados.

Como fazer, então, para interessar ou envolver a família na escola? Várias ações são propostas, as quais estão articuladas pela idéia de que cabe à escola um papel preponderante na reforma social visada. Essa perspectiva aparece em artigos como o intitulado "A missão da escola é criar valores socialmente utilizáveis - Vigorosos traços de ensino moderno - 'Método de problemas e métodos de projeto"' (grifos no original), em que se afirma que "à escola moderna cabe a obra de assistência social, no ponto de vista econômico, higiênico, cívico, moral" (Ano II, n.15, 1926, p.238-239), em que se alude ao comentário do prof. José Escobar referente ao inquérito sobre instrução realizado em São Paulo.

Porém, é sobretudo quando se trata da "reforma" das camadas mais pobres da sociedade, particularmente no que se refere à higiene e à alimentação, que a dimensão reformadora da escola adquire maior consistência. No artigo "Escola Nova - problemas a resolver", o assistente técnico do Ensino, Oscar Arthur Guimarães, depois de discorrer longamente sobre a importância de a escola contribuir para a garantia de um corpo saudável para seus alunos, dizendo ser este o grande problema a ser resolvido pela escola nova, conclui afirmando:

"A escola não poderá ir diretamente auxiliar as classes pobres, facilitando-lhes meios de vida e provendo-as de alimentos. Mas poderá suavizar o mal, fornecendo regras de economia e de rendimento maior no trabalho" (Ano IV, 35, 1929, p.45).

Nessa cruzada reformista dos costumes e das pessoas, a mulher é identificada como a grande responsável por garantir a boa ordem no lar e, sobretudo, por possibilitar 
que a família passe a incorporar, cada vez mais, referências escolares/escolarizadas de gerir o mundo doméstico e a educação dos filhos. Para isso, também, e principalmente, as mulheres precisam ser reeducadas, pois, para bem educar, não basta amar, é preciso conhecer e compreender as necessidades infantis.

Assim, ao comentar uma conferência realizada na Alemanha, com o objetivo de interessar os pais pela educação dos filhos (no lar e junto aos professores), a revista, pondo em circulação o artigo "A cooperação das famílias na educação", ao mesmo tempo em que reafirma que, para orientar e conduzir a criança, é preciso ter-lhe amor e saber compreendê-la, explicita o grande problema detectado nas relações com os pais:

"É impossível educar nas escolas quando os pais de nossas alunas são eles próprios mal educados; por conseguinte, qualquer tentativa nossa para educar estas crianças as poriam em atrito com os pais e parente, e, por meio destes, conosco educadores" (Ano II, n.15, 1926, p.207).

Visando superar o problema, os legisladores e a própria revista serão pródigos na proposição de instituições escolares que incentivem e permitam as famílias aproximarem ou participarem da escola, as quais possibilitariam a educação dos pais (principalmente, das mulheres).

Previstas já no Regulamento do Ensino Primário, de 1925, às Associação de Mães e organizações congêneres será dada grande atenção. Nas matérias que versam sobre o assunto, será reafirmado, sempre, o lugar sagrado da mulher/mãe na educação da criança. Sobre isso, seria interessante citar uma conclamação do próprio presidente do Estado, Melo Viana, às mães mineiras, publicada no número 02 da revista. Dizia ele:

"O governo ouvirá, sempre, sobre a eficiência e moralidade da família (...) para promover ou inspecionar o ensino, enfatizando a 'missão educador' e o importante papel desempenhado pelas mães, nas 'democracias', 'de formadoras do caráter dos cidadãos', ressaltando que o manancial mais puro das energias cívicas e das virtudes morais - é hoje verdade universal proclamada - brota da educação do lar pela palavra materna. (...) é na obediência à doce autoridade das mães e nos conselhos constantemente derramados do seu coração que os homens aprofundam o culto da lei, para respeitar e obedecer aos seus verdadeiros representantes"(apud Borges, 1993:62-3).

Com este espírito, no ano seguinte, por ocasião da preparação e realização do Congresso de Instrução Primária, a revista publica as teses discutidas, sendo que uma delas levanta a seguinte questão: “10ํ) Haverá vantagem em que nos grupos escolares se organize conferências de vulgarização pedagógica, a fim de esclarecer os pais sobre os problemas da psicologia infantil, o papel da escola e a colaboração necessárias entre a família e o mestre?" (Ano II, 22, 1927:480).

A resposta foi, evidentemente, afirmativa, reforçandose a perspectiva da educação dos pais pela escola. No entanto, no decorrer da propaganda da reforma, que teve na revista e no órgão oficial do Estado, o jornal Minas Gerais, seus principais meios, alguns professores observam a necessidade de explicá-la às próprias famílias, e não apenas aos professores. É com este intuito que na seção "Daqui e dali", do número 35 da revista (1929), aparece um artigo com o significativo título de "A reforma do ensino primário revelada aos leigos", que tem como epígrafe o seguinte enunciado, debitado a Camões: "Quem não conhece a arte, não n'a estima." No texto, fruto de uma Conferência realizada pelo professor Waldemar de Almeira Barbosa, da escola Normal de Dores do Indaiá, o autor principia por dizer que não tem "a pretensão de trazer luzes ao professorado primário", pois este já estava sendo alvo de outras ações, e continua:

"Mas os senhores pais de família, que não estão na obrigação de a examinar a fundo, mas que se não furtam a julgamentos muitas vezes falsos e errôneos sobre ela, merecem que se lhes dêem algumas explicações, que se lhes esclareçam as dúvidas.

Já ouvi de pais e mães de família esta queixa: 'No meu tempo ensinavam isso no $2^{\circ}$ ano'; ou então: 'No primeiro ano eu já sabia aquilo'.

E com toda sua lógica vão deduzindo: o ensino antigo era melhor.

Não! Julguemos com mais prudência."

Depois de explicitar as complexas mudanças pelas quais passava a educação mineira, o professor conclui que "esta queixa dos pais se justifica pela ignorância dos métodos atuais do ensino". Em seguida, o professor Waldemar expõe ser natural tais incompreensões, citando Decroly como exemplo de quem, também, foi incompreendido em suas propostas por reformar a escola.

Em outra parte do texto, o autor chama a atenção para o processo de formação de professores, instaurado principalmente pela Escola de Aperfeiçoamento de professores, organizada no bojo da reforma, dizendo o quanto ela irá incidir sobre a melhoria da ação docente junto aos alunos. No entanto, como que dialogando com os pais, ele adianta: 
"Mas não precisamos esperar. Agora mesmo: observai se vossos filhos ou vossos netos têm aquele horror que tínheis à escola.

Notai que não é mais preciso obrigá-lo a ir à escola. Eles amam a escola.

Será que a mentalidade infantil do vosso tempo e a de agora tenham se transformado inteiramente?

Não, a escola é que foi transformada.

A escola antiga era freqüentada com repulsa.

A escola de hoje, é um gozo freqüentá-la.

O que não há é perfeita compreensão de parte dos que se queixam da reforma do ensino.

E é o que precisa haver.

É necessário que os pais de família se acostumem a visitar freqüentemente as escolas onde seus filhos são educados.

É o Estado que abriu estas escolas para vossos filhos.

É o Estado que deseja que visiteis os estabelecimentos onde se educam vossos filhos."

É interessante observar o teor e a estrutura do discurso escolhidos pelo professor para "dirigir-se" às famílias. Há como que um diálogo, em que apenas uma das partes expõe seu ponto de vista, no qual busca mostrar, ou construir, no ato mesmo do discurso que a institui, que a mudança pretendida na escola já se realizou. Observa-se, também, que o autor lança mão, desde o título, de referências claramente religiosas - leigos, revelada, luzes... -, as quais, sem dúvida, são uma marca do processo de reforma mineiro. Construir e mostrar uma imagem de escola como um lugar agradável, saudável, alegre, onde as crianças gostam de ir e ficar, e, mais ainda, demonstrar que esta é fruto da ação do Estado, é uma operação em curso desde os finais do século XIX, e que tem, no momento estudado, uma grande relevância. Porém, não bastava isso. Era preciso intensificar a educação dos pais.

"Para isso criou a instituição admirável que é o ‘auditorium' quinzenal, a fim de que as famílias indo assisti-lo, conheçam o método atual de ensino, tão diferente daquele pelo qual aprenderam, e exclamem como tantas pessoas já têm exclamado: Oh! Se ensinassem assim no meu tempo! Como o ensino é alegre, atraente, como prende a atenção dos meninos! O que compete aos pais de família, com especialidade, às mães é continuar em casa a obra de educação que se processa na escola.

Estais vendo o grande interesse que os poderes públicos estão tendo com a instrução.

Deveis contribuir com vossa parte não desfazendo o trabalho dos professores; pelo contrário, colaborando com eles.
Não vos esqueçais nunca que a primeira educação é a das mães" (Ano IV, 35, 1929:103).

Além de trazer os pais até a escola, é preciso que a escola vá até as famílias, que as conheça. Num longo texto que trata do Ensino da língua portuguesa, no subtítulo que trata da Escola ativa, o professor Firmino Costa, citado anteriormente, chama a atenção para o que seria $a$ nossa escola ativa. Dizia ele:

"A nossa escola ativa será aquela, cujo professor conheça cada um de seus alunos; a família do menino; o ambiente familiar; a casa de residência; suas condições higiênicas; grau de inteligência do aluno; qual o seu caráter; se é sadio e asseado; se tem boa alimentação; a que horas se deita e se levanta; se dorme em quarto arejado; se fuma ou se tem outro vício; se é feliz ou infeliz (...).

Em outras palavras, os professores hão de tornar-se profissionais do ensino, verdadeiros advogados da causa dos alunos" (Ano IV, 35, 1929).

Já no artigo "Instituições escolares", que é "supostamente" o relato de uma aula da professora Amélia de Castro Monteiro, na Escola de Aperfeiçoamento, em 1929, ao discorrer sobre a importância do Clube de Leituras, da comemoração das datas nacionais, das atividades nas férias, das excursões e da merenda na escola, a autora evidencia a necessidade de se atuar, também, no tempo de férias dos alunos, alargando, assim, o tempo da educação escolar e acompanhando a criança, indiretamente, no próprio ambiente familiar. ${ }^{4}$ Ao justificar a utilidade de várias ações sugeridas para as férias escolares dos alunos, ela afirma que as mesmas são: “(...) 8º Meio de se evitar férias mal gozadas, passadas em geral em tropelias, más companhias, depredações e vagabundagem; 9o Meio de se conservarem os hábitos e atitudes seguidos e inculcados na escola" (Ano IV, 35, 1929:68).

Se, como está sendo observado, boa parte dos discursos incide sobre a necessidade de educação dos pais, não menos importância foi dada à estratégia de se utilizar o próprio aluno como intermediário entre a escola e a família. Conquanto esta perspectiva não seja nova, uma vez que que dá continuidade a práticas já existentes, como, por exemplo, os boletins escolares instituídos em Minas Gerais alguns anos antes, no caso verificado há uma inovação no sentido de que é a própria ação educativa do aluno que é enfatizada.

No mesmo artigo de Firmino Costa citado anteriormente, há uma interessante reflexão sobre isto: "A escola ativa precisa da colaboração dos pais e das mães de família.

A reforma do ensino quer que a escola seja uma sociedade em miniatura. Dando outro sentido à expressão, posso 
dizer que, além do professor e dos alunos, são sócios dessa sociedade os pais e as mães de família. Ora, não se admite deixarem os sócios de concorrer para o bem da sociedade a que pertencem. Ao gerente da sociedade, que é o professor, incumbe fazer dos alunos intermediários junto das famílias, para granjear a colaboração delas. Por meio dos filhos, que são os alunos, educados na escola ativa, esta conseguirá a referida operação.

A escola ainda não se faz reconhecida dos alunos, porque tem estado fora o circuito de seus interesses, quando somente por intermédio deles poderá aproximar-se das família, sendo este o primeiro passo para a colaboração" (Artigo "Língua Portuguesa", Ano IV, 35, 1929:84).

Esta mesma ênfase aparece no artigo "A criança também pode ter influência na educação dos pais. Como se exerce esta influência. Observações interessantes", traduzido do L'école et la vie. Nele a referência à França parece indicar, ao mesmo tempo, a importância e a atualidade do tema. Dizia o texto:

"Recentemente um inspetor escolar da França salientou, em conferência pública, a parte que a criança desempenha na educação de seus pais. Pode-se afirmar, sem hesitação, disse o zeloso propagandista, que no estado presente do marasmo social e do afrouxamento dos laços familiares que a criança é o agente mais eficaz da reconstituição ou da reeducação da família" (Ano II, n.13, 1926:126).

Em seguida, o autor lembra que este expediente havia sido largamente utilizado pela igreja, explicitando a apropriação, por parte da escola, de mecanismos utilizados por aquela:

"Outrora, os educadores religiosos souberam aproveitar a influência da criança sobre os pais, para conduzir estes à submissão mais completa às prescrições eclesiásticas ou evangélicas. O menino católico na época da primeira comunhão faz, muitas vezes ainda, obra de proselitismo inspirado, que não é indiferente às mães e às irmãs, às vezes aos pais e irmãos. Como, pois, não há de conseguir o educador leigo fazer penetrar na família idéias de moral, de civismo, de higiene ou mesmo de noções de ordem científica e técnica? A criança é, naturalmente, comunicativa; faz alarde de um pequeno conhecimento recentemente adquirido; possui, às vezes, admiráveis aptidões educativas (...).

Nem sempre, entretanto, os pais escutam com atenção a criança tagarela; mas esta não se deixa vencer com facilidade: a palavra do mestre tem mais autoridade do que a dos pais, cuja ignorância é manifesta" (Ano II, n.13, 1926:126-7).
A ação da criança, aspecto dos mais centrais da escola ativa, tal qual a compreende e divulga a Revista do Ensi$n o$, extrapola a própria escola e as atividades de ensino e aprendizagem para incidir diretamente sobre os pais, sobre suas famílias. Revela-se, aqui, toda uma problemática que extrapola as possibilidades dessa pesquisa e, mesmo, de pesquisas com este tido de fonte: as diversas modalidades e intensidade das relações estabelecidas entre as famílias e as escolas, tendo o aluno como eixo articulador ou, nas palavras de Perrenoud (1987), como go-between, ou seja, o aluno como mensageiro e mensagem na relação escola e família.

No caso da reforma mineira, e mesmo de outros processos reformistas em curso no período, o estudo do lugar reservado e das ações projetadas para as próprias crianças na reeducação de suas famílias talvez pudesse nos revelar facetas interessantes das concepções acerca da própria infância no interior do pensamento escolanovista, bem como nos possibilitar de acompanhar um momento pretendido como privilegiado de ação da escola sobre a sociedade.

Assim, uma boa pista para estudar a relação entre a escola e a família no interior dos movimentos e das experiências escolanovistas seja a de trabalhar num duplo movimento: verifica a amplitude das práticas que recortam, identificam, dão relevo e sentido ao tema e por investigar os lugares reservados aos sujeitos - especialmente à mulher e à criança - no interior da cruzada reformista desenvolvida pelos escolanovistas em relação à família e ao conjunto da sociedade.

\section{NOTAS}

E-mail do autor: lucianom@fae.ufmg.br

1. Este é o caso, por exemplo, das referências sempre elogiosas à École des Roches, organizada por E. Demoulins, na França.

2. Trata-se do projeto "Escolarização, culturas e práticas escolares", que conta com o apoio do CNPq, da Fapemig e da UFMG.

3. Isto, do que parece, pode ter várias razões, dentre estas as diferenças marcantes entre os dois veículos: enquanto a Revista do Ensino é claramente um órgão de divulgação e de formação dos professores, a RBEP tem como objetivo a divulgação de artigos e estudos de fundo, cujos autores e destinatários são, em tese, pesquisadores e especialistas em educação.

4. Esta questão, bem como a necessidade de educação da mulher para lidar com os filhos, é observada por Gouvêa (1997), ao trabalhar com outras fontes, notadamente com a literatura infantil.

\section{REFERÊNCIAS BIBLIOGRÁFICAS}

ALVARES-URIA, F. e VARELA, J. Arqueologia de la escuela. Madrid, Las Ediciones de la Piqueta, 1991. 
BICCAS, M. de S. Da revista à leitura: a formação de professores e a conformação do campo pedagógico em Minas Gerais (1925-1940). Belo Horizonte, $\mathrm{FaE} / \mathrm{CNPq}, 1999$, mimeo.

BORGES, V.L.A. A ideologia do caráter nacional da educação em Minas Gerais: Revista do Ensino (1925-1929). Dissertação de Mestrado. Campinas, Faculdade de Educação da Unicamp, 1993.

CARVALHO, M.M.C. de. "Uso do impresso nas estratégias católicas de conformação do campo doutrinário da pedagogia (1931-1935)". Cadernos da ANPEd, 7, 1994, p.41-60.

. Molde nacional e fôrma cívica. São Paulo, CDAPH-Ifan, 1998.

CUNHA, M.V. da. "A escola renovada e a família desqualificada: do discurso histórico-sociológico ao psicologismo na educação". Revista Brasileira de Estudos Pedagógicos, 186, maio-agosto 1996, p.318-345.

FARIA FILHO, L.M. "Estado, cultura e escolarização em Minas Gerais no século XIX. In: VIDAL, D.G. A memória e a sombra. Belo Horizonte, Autêntica Editora, 1999, p.117-136.

. Dos pardieiros aos palácios. Passo Fundo, Ed. UPF, 2000, no
GOUVÊA, M.C.S. O mundo da criança: a construção da infância na literatura. Tese de Doutoramento. Belo Horizonte, Faculdade de Educação da UFMG, 1997.

GVIRTZ, S. (comp.). Escuela nueva en Argentina y Brasil - visiones comparadas. Buenos Aires, Miño y Dárita Editores, s.d.

MONTANDON, C. e PERRENOUD, P. Entre parents et enseignants: un dialogue impossible? Paris, Peter Lang, 1987.

NUNES, C. A escola redescobre a cidade. Tese de concurso para Prof ${ }^{\mathrm{a}}$ Titular. Rio de Janeiro, UFF, 1993.

PATRI, A. Vers l'école de demain. 2ª ed. Paris, Hachette, 1919.

PERRENOUD, P. “Le Go-Between: entre famille et l'école, l'enfant messager et message". In: MONTANDON, C. e PERRENOUD, P. Entre parents et enseignants: un dialogue impossible? Paris, Peter Lang, 1987, p.49-87.

SOUZA, R. de C. Escola nova e disciplina: uma aproximação. Belo Horizonte, FaE-UFMG, 1999, mimeo.

VICENT, G. (dir.). L'éducation prisonnière de la forme scolaire? Lyon, Presses Universitaires de Lyon, 1994. 